\title{
POR UMA NOVA DEMOS. A INSERÇÃO DA COMUNIDADE LGBTQIA+ NA GÊNESE LEGISLATIVA BRASILEIRA
}

\author{
FOR A NEW DEMOS. THE INSERT OF THE LGBTQIA + COMMUNITY IN \\ BRAZILIAN LEGISLATIVE GENESIS
}

\author{
Douglas Vinícius de Oliveira Santos ${ }^{1}$ \\ Sander Prates Viana ${ }^{2}$
}

RESUMO: A origem da democracia remonta um contexto de privilégios. Após milênios de desenvolvimento de institutos representativos e regimes políticos democráticos, as Casas Legislativas brasileiras ainda possuem o perfil elitista. Resta evidente que a cota eleitoral de gênero enquanto ação afirmativa já prevista na legislação eleitoral é o instrumento jurídico capaz de solucionar a sub-representatividade aqui enfrentada. Contudo, ante a carência legislativa no presente sentido, a legitimidade política LGBTQIA $^{+}$fica condicionada ao amparo por norma específica estatal, visto que romper com sistemas que endureçam as relações sociais é dever do Estado. Fica explícito que a ausência de enrijecimento de políticas públicas que estimulem a efetivação de direitos de um determinado segmento social pode ser entendida como o resultado de um deficiente amparo legislativo conferido pelo sistema político nacional aos movimentos contra-hegemônicos, ocasionando ineficácia dos preceitos concretos de democracia.

Palavras-chave: Cotas eleitorais de gênero no Sistema Proporcional. Representação Política LGBTQIA $^{+}$. Recrutamento Eleitoral.

ABSTRACT: The origin of democracy goes back to a context of privileges. After millennia of development of representative institutes and democratic political regimes, as the Brazilian Legislative Houses still have an elitist profile. It remains evident that the gender electoral quota as an affirmative action already provided for in the electoral legislation is the legal instrument capable of solving the underrepresentation faced here. However, before a legislative deficiency in this sense, LGBTQIA + political legitimacy is conditioned to the protection of a specific state rule, since breaking with systems that support social relations is the duty of the State. It is clear that the lack of tightening of public policies that encourage the realization of the rights of a certain social segment can be understood as the result of a deficient legislative support given by the national political system to movements against hegemonic, causing ineffectiveness of the concrete precepts of democracy.

Keywords: Gender Electoral Quotas in the Proportional System. LGBTQIA ${ }^{+}$Political Representation. Electoral Recruitment.

Graduando em Direito, Faculdade Nobre de Feira de Santana (FAN), douglasvinn@gmail.com.

Mestre em Geografia (Universidade Federal da Bahia), Faculdade Nobre de Feira de Santana (FAN), sanderprates@hotmail.com 


\section{INTRODUÇÃO}

A atual configuração do sistema político-representativo nacional revela, obviamente, características sintomáticas enquanto produto do meio social que este supostamente representa. Diante da atual pseudoneutralidade governamental quanto ao reconhecimento à diversidade de gêneros não hegemônicos e, consequentemente, enfraquecimento de políticas públicas aptas a efetivar direitos desse segmento social ratifica-se, por meios institucionais, a obstrução por ambição política e carreira pública a estes indivíduos.

Embora os regimes democráticos ocidentais tenham se fortalecido diante do ideal de representatividade para efetivar um governo feito pelo/para o povo, as candidaturas eleitorais - fase pré-eleitoral -, já denotam tais barreiras pela própria dinâmica de exclusão social e pelos filtros institucionais seletivos, resultando na marginalização representativa das instituições nacionais.

Apesar do acréscimo do número de candidaturas registradas por sujeitos que disputam a arena em prol da diversidade sexual, os avanços obtidos pela agenda Lésbica, Gay, Bissexual, transexuais ou Transgênero e Travestis, Intersexo e Assexuais (LGBTQIA $\left.{ }^{+}\right)^{3}$ demonstram que não é do Poder Legislativo que surgem as principais garantias ao segmento. Ao contrário, a esfera legislativa passou de bloqueada às iniciativas da comunidade à legitimadora explícita na restrição de direitos.

Ao passo que outros setores sociais acompanham a politização das mais variadas manifestações de identidades sexuais e de gênero, a política não vem alcançando a mesma posição, posto que acaba por instituir um sistema político-representativo anômalo, alimentando a descrença do papel político como meio de transformação social.

Com vistas ao aprofundamento do assunto, o presente artigo tem como tema Representatividade Legislativa LGBTQIA $^{+}$. O problema da pesquisa consiste em: A atual configuração do sistema representativo garante a participação da comunidade $\mathrm{LGBQIA}^{+}$aos cargos eletivos do sistema proporcional? Neste sentido, a relevância trazida reside em, apesar da ausência de uma doutrina sólida e específica sobre o objeto da pesquisa, facilitar a compreensão acerca das dificuldades encontradas por grupos sociais não heteronormativos em se apropriar da vida política.

\footnotetext{
3 Historicamente, GLS foi a primeira sigla utilizada para identificar um movimento fora do padrão heteronormativo. Em crescimento desde a década de 9o, a sigla atualmente representa o movimento político e social que engloba a inclusão de diversas orientações sexuais e identidades de gênero. Recentemente, é utilizada a sigla LGBTQQICAPF $2 \mathrm{~K}+$. Contudo, para fins didáticos será empregada a sigla LGBTQIA ${ }^{+}$que sintetiza a mescla de todas as demais.
} 
Por essa razão, é de suma importância questionar o atual contexto político-social, no qual as variadas formas de subjetividades se encontram enfraquecidas diante da pseudoneutralidade governamental. Nesse sentido, a presente pesquisa encontra respaldo no mundo jurídico-normativo ao propor mecanismos institucionais instrumentais e alternativos de legitimação política aos movimentos contra majoritários de representação e, consequentemente, expansão material do Texto Constitucional.

\section{O Exercício da Cidadania e as Cotas Eleitorais de Gênero}

\section{I A Igualdade Universal dos Sujeitos do Projeto Liberal, a Emancipação do Sujeito Político e a Teoria Política Feminista}

A acepção de democracia tem origem na Grécia Antiga inserida em contextos elitistas da época. Entretanto, costuma-se afirmar que a definição moderna de cidadania representativa possui raiz liberal. Em termos históricos, partindo-se de estudos da Teoria Política, foram as matrizes de pensamento oriundas das revoluções burguesas dos séculos XVII e XVIII responsáveis por atribuir à cidadania o epicentro das relações políticas e normativas daquela época, ideologicamente centro das relações sociais atuais.

A lógica jurídico-política das instituições contemporâneas possui matrizes nos projetos liberalista e iluminista do século XVIII, repercutindo na configuração institucional do espaço público moderno. Tais correntes ideológicas resultaram numa nova concepção de Estado e novas manifestações das relações de poder ${ }^{4}$, firmando limites da coisa pública e seus critérios de participação ao elevar a supremacia do indivíduo, voltada mais ao individualismo como nova forma de ver e entender o sujeito à noção de que todos nascem livres e iguais.

$\mathrm{Na}$ visão do Liberalismo Clássico5, o status social como predecessor na forma peculiar de organização das relações sociais do Antigo Regime deu lugar a um contratualismo baseado nos

\footnotetext{
${ }^{1} \mathrm{Na}$ visão de Foucault toda relação de poder se reveste de um discurso que o justifique. É inserida nessa concepção que as matrizes de pensamento liberais firmam novas estratégias subjetivas da esfera social ao manipular as novas estratégias de força, seja para nutri-las ou bloqueá-las.

${ }^{2}$ Com a expansão dos ideais liberais o conflito de interesses entre a burguesia e a monarquia absolutista do século XVII despontaram da vida prática teorias políticas. Cunhou-se o chamado "Liberalismo Clássico" para representar a pioneira corrente teórica responsável por salvaguardar os interesses da classe burguesa emergente, tendo como maior expoente John Locke, cujas obras nutriram a Revolução Americana e a Revolução Francesa.
} 
axiomas filosóficos do igual e do fraterno. Ocorre que a teoria política e filosófica baseada na fictícia relação contratual originária, que cunhou a concepção moderna de cidadão, aplicada às configurações sociais atuais, tornou evidente que a falsa ascensão da igualdade universal dos sujeitos permitiu que enormes desigualdades entre esses sobrevivessem.

Um dos objetivos cruciais da teoria política é identificar e defender qual o melhor regime político a ser aplicado na esfera pública enquanto arena onde litigam conflitos de interesses de classes. Nas últimas décadas é de responsabilidade da Teoria Feminista a análise acerca dos fenômenos políticos utilizando o gênero ${ }^{6}$ como método interpretativo.

Dentro da Teoria Política Feminista, o espaço público se compreende como o fundamental recurso de exercício do poder patriarcal. Assim, são os homens responsáveis por definir, não só o próprio objeto teórico, mas quais os modelos de política e cidadania devem ser adotados. Se há quem defenda que a arena pública é regida por uma classe dominante, as teóricas feministas apontam que tal classe é, evidentemente, a masculina. (Ramos, 2014).

Ocorre que, as falsas abstrações que o liberalismo atribuiu à natureza humana não resiste se comparadas aos indivíduos inseridos em uma estrutura social não homogênea, desigual e dotada de hierarquia política. Essa macroestrutura social liberal, portanto, renega as subjetividades dos sujeitos - gênero, raça e classe.

Para a doutrina feminista, o triunfo dos ideais liberais e iluministas de abstração do sujeito, liberdade e igualdade universais representou para as mulheres, em vez de empoderamento, nova forma institucionalizada de subordinação. Nesse diapasão, o sistema jurídico presente no contratualismo visa justificar e manter o liberalismo enquanto ideologia. Se o contrato social visa firmar a estrutura político social "a experiência feminina sugere que a fraternidade e igualdade revelam-se como hipocrisia narrativa, pois, sob a falsa neutralidade legitima-se relações de dominação" (Ramos, 2014).

Foi levando em conta esses princípios falsamente universalistas do liberalismo que a teoria política feminista elaborou uma crítica peculiar claramente anti-liberal. Uma interessante análise é a legada por Carole Pateman, para quem o gérmen da crítica ao contrato originário encontra-se exatamente na preocupação de como a

3 O gênero é utilizado dentro da teoria política feminista como método analítico de interpretação das percepções da vida social como o comportamento humano, distribuições de poder no trato social e as intersecções das relações sociais entre gênero como constructo política. 
liberdade civil daí derivada possui embutido o direito patriarcal moderno que cria a sujeição feminina. (RAMOS, 2014, p. 67).

Depreende-se, portanto, que a gênese da cidadania contemporânea tem retirado das mulheres, por intermédio de mecanismos jurídicos institucionalizados, colocando-as à marginalização de seus direitos políticos, e, consequentemente, de participar ativamente da direção da máquina pública. Desse modo, a democracia no mundo contemporâneo não apenas produziu um discurso teórico, na vida prática é fácil compreender que esta também erigiu, à medida que se difundia, a diferença baseada no gênero.

\title{
2.2 A Sistemática das Cotas Eleitorais de Gênero aplicadas ao Sistema Proporcional
}

O sistema eleitoral proporcional é visto como resposta ao aperfeiçoamento da qualidade de representação política, pois, se debruça em efetivar a vontade da maioria. Embora possibilite a representação dos mais variados segmentos sociais, não deixa de estimular uma disputa partidária, pelo menos no âmbito interno, permitindo que candidaturas registradas com maior capital econômico alcancem maior notoriedade.

Se o emblema da democracia é dar força e voz à vontade da maioria, é inevitável, senão, lógico, que se tornem politicamente neutralizadas e inaudíveis as necessidades daqueles que, em primeira análise, não fazem parte de tal parcela predominante ${ }^{4}$.

\begin{abstract}
A formação do corpo legislativo não deve ser expressada via maioria, pois o uso desse tipo de regra nas eleições tira da minoria o direito de exercer a sua porção correspondente no poder. Quando há no parlamento uma representação proporcional de todas as correntes de opinião existentes no demos, é possível que ideias divergentes sejam confrontadas. O governo de todos por todos não significa homogeneidade, Alencar (1991) compreende que é impossível na sociedade humana haver uma única opinião, mas ele propõe que do embate no congresso entre vozes discordantes e de posições divergentes, o alvitre que obtiver o maior número expressará a vontade universal, porque todos participaram. (BRITO, 2016, p. 12).
\end{abstract}

Assim, sob o perigo de uma parcela, ainda que majoritária, legislar seus interesses unicamente, surge a necessidade de atribuir legitimidade à parcela minoritária, sob pena de configuração de uma aparente democracia. A legislação eleitoral brasileira, como forma de diminuir a sub-representatividade de gênero, pelas razões já expostas, vem implementando regras que visam

\footnotetext{
${ }^{4}$ A inserção das minorias na política brasileira já era objeto de estudo desde I846. Tardiamente, o Brasil é um dos últimos países da América Latina a criar mecanismos de representação feminina no parlamento.
} 
o aumento significativo de candidaturas dos segmentos minoritários nas eleições proporcionais das Casas Legislativas.

Com esteio nos valores atinentes à cidadania e no pluralismo político, fundamentos do Estado Democrático de Direito, entende-se por cota eleitoral de gênero, na visão de Gomes (2020), como sendo a ação afirmativa que visa "espaço mínimo de participação de homens e mulheres na vida política do País".

A Lei de no 9.504 de 1997, Lei das Eleições, expandiu as noções atinentes às ações afirmativas eleitorais. Antes, influenciada por questões debatidas no cenário internacional, a Lei no 9.10o de I995, que ficou conhecida como Lei de Cotas, estabelecia o percentual de vinte por cento de preenchimento de candidaturas por mulheres. Contudo, a referida lei apenas tinha validade para as Câmaras Municipais.

É nesse contexto, que o art. 93 da mencionada norma autoriza o Tribunal Superior Eleitoral, em datas específicas dos respectivos anos eleitorais, antes e posterior as convenções partidárias, a promover a "propaganda institucional, em rádio e televisão, destinada a incentivar a participação feminina, dos jovens e da comunidade negra na política" (Brasil, 1997).

Aumentando de maneira considerável as acepções sobre ações afirmativas aplicadas à realidade eleitoral, a Lei das Eleições atualmente determina em seu art. Io, $\S^{\circ}$ q que as cotas de gênero sejam aplicadas também às Assembleias Estaduais e Câmara dos Deputados, tendo sido estendido o percentual de vinte e cinco por cento previstos na Lei de Cotas para de trinta por cento.

Contudo, no ano de 2009, o dispositivo retro mencionado passou a viger com terminologia "preenchimento por cada partido ou coligação para candidaturas de cada sexo" em substituição à "reserva de vagas" previsto anteriormente. A alteração dada pela novatio legis aumentou consideravelmente os registros de candidaturas, entretanto, não significou efetivamente o aumento da participação feminina nas Casas Legislativas. Infelizmente, além do tratamento diferenciado no apoio intrapartidário, leva-se em consideração a destinação de verbas enquanto fator determinante de êxito eleitoral.

Parte da doutrina ainda tece críticas à nova redação legal por vincular as agremiações partidárias à obrigação de preenchimento do percentual exigido. Ainda, fundamenta não ser realidade distante que pequenos partidos, principalmente em âmbito municipal, não disponham de lista suficientes de interessados ao pleito de modo a satisfazer a ação afirmativa. No entanto: 
O problema, porém, dessa interpretação é que torna sem sentido o estabelecimento da quota de gênero, já que o partido fica desobrigado de preencher o limite mínimo estabelecido. E o que se quer é justamente o preenchimento do referido percentual mínimo, de maneira a se incrementar a participação feminina na política e na ocupação de cargos político-eletivos. $\mathrm{Na}$ verdade, com a mudança da redação do enfocado $\$ 3^{\circ}$, artigo io, da LE é necessário que o cálculo dos percentuais de $30 \% \mathrm{e}$ $70 \%$ se baseie no número de candidatos cujos registros forem real e efetivamente requeridos pelo partido, e não (como ocorria antes) o número abstratamente previsto em lei. (GOMES, 2020, p. 562).

O preenchimento das cotas eleitorais de gênero deve ser observado desde a oficialização do pedido de registro de candidaturas, embora já se tenha precedentes do Tribunal Superior Eleitoral (TSE) vislumbrando a possibilidade de que, a obediência à ação afirmativa em análise, se dê "em data posterior à do limite para requerimento de candidaturas", retificando da lista apresentada pelas agremiações partidárias os nomes nela constantes, seja para acrescer ou para dela excluir (Brasil, 2012).

Dentro dos ditames do processo eleitoral, não sendo atendidos os percentuais previstos em lei, a agremiação será notificada, nos termos do art. II, $3^{\circ}$ 으 da Lei das Eleições, para sanar possível vício existente. Na hipótese de não haver a referida regularização, o Demonstrativo de Regularidade Partidária - DRAP -, será indeferido, restando prejudicado todos os pedidos de registro apresentados pelo partido.

Em expansão aos critérios normativos sobre a cota eleitoral, encontra-se em tramitação o Projeto de Lei no 2.235/2019, de autoria do Senador Luiz do Carmo do Partido Democrático Brasileiro (MDB-GO), que prevê a reserva de cota de $30 \%$ das cadeiras do Parlamento para as mulheres como forma de combater a ausência de representatividade feminina no Brasil que, apesar de maioria eleitora é a menos participativa no processo eleitoral. A propositura dispõe:

Altera a Lei no 4.737 , de 15 de julho de 1965 (Código Eleitoral), para estabelecer a reserva de ao menos trinta por cento das cadeiras de Deputado Federal, Deputado Estadual, Deputado Distrital e Vereador para cada um dos sexos e reservar, quando da renovação de dois terços do Senado Federal, uma vaga para candidaturas masculinas e outra vaga para candidaturas femininas (BRASIL, 2019).

A medida recebeu críticas daqueles que justificaram ser massa de manobra para que os partidos consigam alcançar as verbas oriundas do fundo partidário apenas registrando o percentual exigido sem nenhuma participação feminina ${ }^{6}$. Valendo-se da legislação eleitoral, segundo

\footnotetext{
${ }^{6}$ Ante a ausência de uma resposta legal específica, a ocorrência do abuso de poder político-partidário no preenchimento das cotas de gênero ainda é vista pela doutrina como um fenômeno complexo, tanto da perspectiva processual quanto do material.
} 
Sparemberger (2019), desde 1997 a Lei das Eleições já previa a destinação de reserva de vagas para candidaturas pelos partidos ou coligações de cada sexo na proporção 30-70\%, conforme já discutido, entretanto, a intenção da propositura é a destinação de reserva de cadeiras e não meramente o preenchimento por candidaturas, inclusive, em alternância ao Senado Federal, que por atender aos ditames do sistema majoritário, não encontra-se abrangido pelo art. ı, $\$ 3^{\circ}$ em análise.

Nesse contexto, a fim de reduzir as candidaturas meramente formais e a incidência da “industrialização de candidaturas laranja” femininas, a Lei no 13.165 , de 29 de setembro 2015, alterou a Lei das Eleições e o Código Eleitoral - Lei no 4.737, de is de julho de 1965 - regulamentando os gastos voltados aos incentivos da propaganda e campanha eleitoreiras. Além disso, com a entrada em vigor da minirreforma eleitoral, Lei no ${ }^{\text {13.488, de }} 6$ de outubro de 2017, as configurações atuais a cota de gênero deve ser observada por cada partido, devido ao fim das coligações partidárias no sistema proporcional.

Para Gomes (2020), é indispensável que o regime democrático exija certo nível de consciência política e responsabilidade de seus atores. Embora a ação afirmativa aqui analisada tenha gênese dentro de um contexto que tem por objetivo neutralizar a questão da sub-representatividade eleitoral e incluir a participação feminina nos espaços públicos de poder, a cota de gênero atualmente é interpretada em benefício do gênero menos representado, e não unicamente em prol de candidaturas femininas. Por esta razão, veda-se apenas registro de candidaturas de mulheres na formação da chapa partidária, que, nesse caso, apesar de ser maioria, terá que reservar o percentual legal estabelecido às candidaturas masculinas se baseando no quantitativo real de candidatos efetivos requeridos pelos partidos.

\subsection{Recorde no aumento de registro de candidaturas LGBTQIA ${ }^{+}$nas eleições municipais de 2020}

As eleições municipais de 2020 sofreram significativas alterações em decorrência das excepcionalidades advindas da Pandemia da Covid-19, tendo sido, inclusive, aprovada Emenda Constitucional no 107 com o objetivo de alterar as datas das eleições e os respectivos prazos eleitorais constitucionalmente estabelecidos.

Outro importante fato de notabilidade foi o aumento recorde de candidaturas ligadas à causa LGBT. Embora o sítio de dados do Tribunal Superior Eleitoral forneça quantitativos de registro de candidaturas baseadas nas auto declarações raciais e sexuais dos candidatos, não dispõe de melhores informações acerca das identidades de gênero. 
Vale ressaltar, conforme Brasil (2018), o reconhecimento hermenêutico conferido pelo TSE para que pessoas trans, possam no momento do registro e diplomação de candidaturas se valer do nome social e do gênero com o qual se identifica". Para tanto, a expressão "cada sexo", do art. Io, $\$ 3^{\circ}$ da Lei no 9.504, deve ser interpretada com base no gênero do(a) candidato(a), e não mais exclusivamente pelo sexo biológico. Assim, há a possibilidade de cômputo das candidaturas trans incluídas no gênero que lhes representa nas buscas em bancos de dados.

Segundo informações do Programa Voto com Orgulho (2020) da Aliança Nacional LGBTI+, até o dia quatro de setembro do corrente ano, foram registradas a adesão 585 pré-candidaturas que lutam pela agenda da diversidade de gênero, destas, 569 (97\%) visam cadeiras nas Câmaras Municipais, ao passo que 15 (3\%) pré-candidaturas pleiteiam cargos de chefia do executivo.

Figura I - Gráfico da distribuição dos registros de pré-candidaturas conforme as identidades de gênero nas eleições municipais de 2020 .

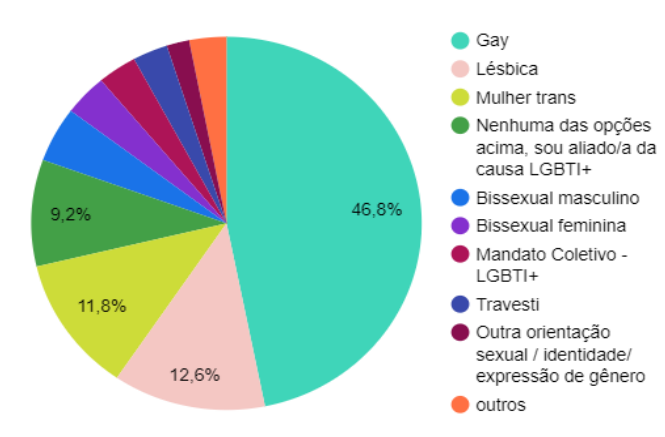

\begin{tabular}{|c|cc|}
\hline Adesões & Cargo & Quantidade \\
\hline Quantidade & Vereador(a) & 569 \\
\hline 585 & Prefeito(a) & 15 \\
\hline
\end{tabular}

Extraído de: Aliança Nacional LGBTI+, 2020.

\begin{tabular}{|c|c|}
\hline Como se Identifica & Quantidade \\
\hline Gay & 274 \\
\hline Lésbica & 74 \\
\hline Mulher trans & 69 \\
\hline Nenhuma das opções acima, sou aliado/a ... & 54 \\
\hline Bissexual masculino & 28 \\
\hline Bissexual feminina & 21 \\
\hline Mandato Coletivo - LGBTI+ & 19 \\
\hline Travesti & 17 \\
\hline Outra orientação sexual / identidade/expre... & 11 \\
\hline Homem trans & 11 \\
\hline Queer & 3 \\
\hline Assexual & 3 \\
\hline Intersexual & 1 \\
\hline
\end{tabular}

\begin{tabular}{cc|}
\hline LGBTI+ ou Aliado(a) & Quantidade \\
\hline LGBTI+ & $521^{\text {ws }}$ \\
\hline Aliado(a) & 63 \\
\hline
\end{tabular}

7 O Supremo Tribunal Federal, na $\mathrm{ADI}$ no 4275 , reconheceu às pessoas trans o direito à substituição do nome e sexo diretamente do registro civil sem a necessidade intervenções cirúrgicas ou de tratamento hormonal, sendo suficiente, para tanto, que haja simples declaração da pessoa interessada. 
Ainda, de acordo com o levantamento feito, 63 pré-candidaturas (го,8\%) se mostraram aliados à causa da agenda e 52I (89\%) são, efetivamente, membros LGBTQIA ${ }^{+}$. Os dados ainda mostram que 274 (46,8\%) são Gays; 74 (12,6\%) são Mulheres Lésbicas; 69 (I1,8\%) são Mulheres Trans; 28 (4,8\%) são Bissexuais Masculinos; 2I (3,6) são Mulheres Bissexuais; Travestis somam I7 (2,9\%); os Homens Trans têm II pré-candidaturas (I,9\%); Queer e Assexuais correspondem o,5\%; demais são Intersexuais $(0,1 \%)$ e outras identidades de gênero não hegemonicamente predominantes.

As informações evidenciadas ainda apontam as porcentagens de pré-candidaturas por partidos políticos. O Partido dos Trabalhadores (PT-I3) e o Partido Socialismo e Liberdade (PSOL5o), conhecidos historicamente pela atuação e defesa do espectro político-ideológico de esquerda e extrema-esquerda, respetivamente, apresentaram maior número concentração de pré-candidaturas, $97(16,6 \%)$ e $92(15,7 \%)$.

Figura 2 - Gráfico da distribuição de pré-candidaturas LGBTQIA ${ }^{+}$conforme representação por partidos políticos.

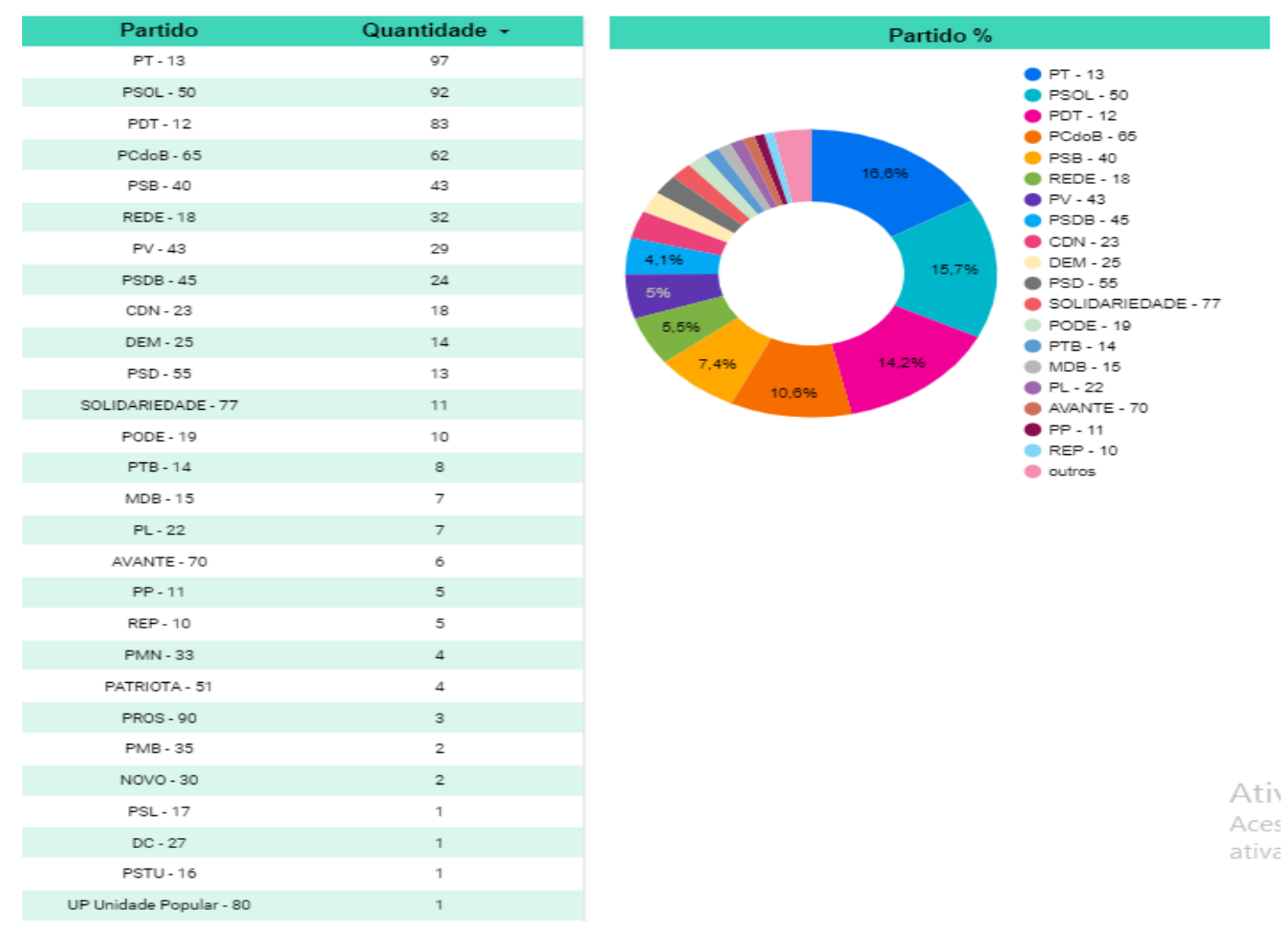

Extraído de: Aliança Nacional LGBTI+, 2020. 
Além dos primeiros posicionados, chama a atenção os próximos colocados no ranking ${ }^{7}$. O Partido Democrático Trabalhista (PDT-I2) com 83 pré-candidaturas (14,2\%), o Partido Comunista do Brasil (PCdoB-65) com io,6\%, o Partido Socialista do Brasil (PSB-40) com 7,4\%, o Partido REDE (REDE-18) com 5,5\%, e o Partido Verde (PV-43) com 5,5\%; todos de matrizes ideológicas alinhadas à centro-esquerda, ocupam, junto com o primeiro e segundo colocados supramencionados, as sétimas primeiras colocações, o que demonstra o estreitamento do diálogo das necessidades da agenda LGBTQIA $^{+}$com o espectro-ideológico da esquerda.

O Partido da Social-Democracia Brasileira (PSDB-45) ocupa a oitava posição, com 4,1\%, seguido do Partido Cidadania (CDN-23) com 3,8\% e o Partido Democratas (DEM-25) com 2,4\% de pré-candidaturas, conhecidos pelos pelo alinhamento às matrizes de pensamento de direita, fechando o ranking dos dez primeiros colocados.

Figura 3 - Gráfico de candidaturas LGBTQIA ${ }^{+}$eleitas conforme agremiação partidária.

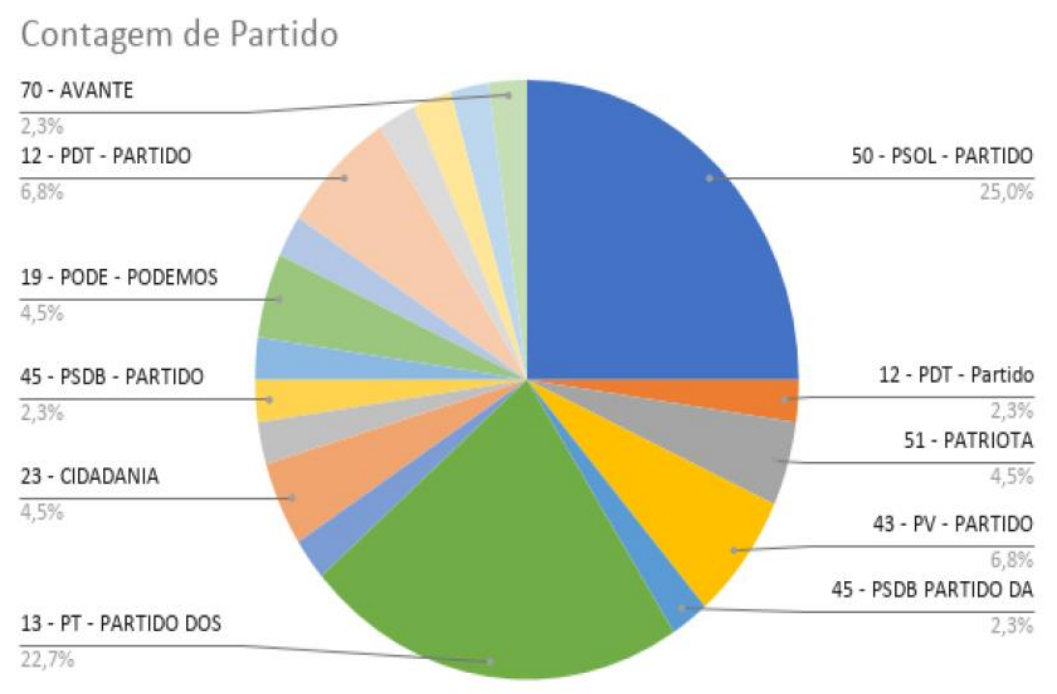

Extraído de: Aliança Nacional LGBTI+, 2020.

\footnotetext{
${ }^{8} \mathrm{Nas}$ configurações político-partidárias atuais, torna-se difícil falar em espectros ideológicos homogêneos de esquerda e direita pela própria dinâmica das linhas de apoio partidário. $O$ tratamento conferido às homossexualidades desde a Ditadura Civil-Militar pela direita, até os presentes dias, sempre foi muito bem delineado, embora, lentamente venha abrindo diálogo com a agenda em prol das diversidades de gênero. Ao mesmo tempo, parcela da frente esquerdista, mesmo tendo empregado discriminações sexuais àquela época, é responsável, atualmente, pelos principais avanços da agenda LGBTQIA+ na América Latina.
} 
Após o pleito das eleições municipais, segundo os resultados colhidos pelo Programa Voto com Orgulho (2020), do montante geral de votos válidos, candidaturas LGBTQIA ${ }^{+}$receberam 450.864 (quatrocentos e cinquenta mil, oitocentos e sessenta e quatro) votos, tendo sido eleitas 48 (quarenta e oito) candidaturas e 93 (noventa e três) suplências. Partindo da análise políticopartidária, o PSOL figura como a agremiação que mais elegeu candidatos, com 25\%; em segundo lugar está o PT, com 22,7\% seguido do PDT, na terceira posição, com 2,3\% de candidaturas eleitas 9 .

Embora historicamente carente de representatividade política, a problemática eleitoral vislumbrada através do recorte de gênero nunca foi encarada como uma preocupação de Estado, pois, se assim o fosse ameaçado estaria o poder que o legitima. As proposituras supramencionadas, enquanto realidade jurídica eleitoral abre precedentes para que a ideia central seja analogicamente estendida por à comunidade LGBTQIA $^{+}$na criação de uma política afirmativa de gênero mais específica.

Se as mulheres sofrem o estigma da sub-representatividade política nos espaços públicos de tomada decisão por ser a classe masculina responsável pela definição dos modelos de política e cidadania a serem adotados, tendo como aspecto distanciador do sexo oposto a condição "ser mulher", a comunidade LGBTQIA $^{+}$, desprovida de qualquer representação, causa aversão à hegemonia dominante por não compartilhar as mesmas expectativas e construções culturais do gênero que lhe é semelhante. Indiscutíveis, portanto, são os abismos jurídico-eleitorais existentes enquanto reflexos das intersecções sociais entre tais segmentos citados.

Não díspar do que ocorre nas realidades da esfera privada estrita aos sujeitos, essa macroestrutura quando analisada sob a ótica da esfera pública evidencia a dominação das candidaturas LGBTQIA $^{+}$, discriminando-as. Além disso, os filtros criados pelas próprias agremiações partidárias, obviamente lideradas por homens cis-heterossexuais muitas vezes não abertos ao debate da luta sexual e de gênero, apenas solidificam não apenas esta, mas, tantas outras desigualdades historicamente construídas.

\footnotetext{
9 Partindo-se da análise das cidades, São Paulo e Belo Horizonte obtiveram votações expressivas reconhecidas nacionalmente elegendo Érikca Hilton e Duda Salabert, respectivamente, ao legislativo municipal. Linda Brasil, em Aracaju, foi a candidata mais votada dentre todos os concorrentes ao pleito local. Os dados mobilizam a comunidade pela distância da realidade onde, atualmente, apenas dois parlamentares LGBTQIA ${ }^{+}$ ocupam cadeiras no Congresso Nacional, Davi Miranda (PSOL), suplente do ex-deputado Jean Willys (Deputado Federal) e Fabiano Contarato (REDE), no Senado Federal.
} 
Muitas vezes o recrutamento eleitoral do campo político se dá de forma pouco receptiva à pauta da agenda $\mathrm{LGBTQIA}^{+}$fazendo com que grande parte das pretensões dos votos seja tolhida por candidatos que correspondem ao perfil dominante já mencionado. Ainda, impera a discussão acerca da cisão "entre representação descritiva e representação substantiva" (Feitosa, 2017) quando apesar do candidato se reconhecer LGBTQIA ${ }^{+}$, não se encontra alinhado às agendas da militância da classe a que politicamente pertence.

Segundo Feitosa (2017), essa migração à esfera pública ainda é marcada por normatização, controle dos corpos, política de disciplina e por discursos religiosos e científicos inferiorizantes. São tantos os entraves, que a neutralização e aniquilamento da representatividade política das identidades sexuais e de gêneros não hegemônicos segregam a atuação direta dos indivíduos desse segmento social na máquina pública. Ironicamente, não é difícil encontrar aqueles que defendem que pessoas LGBTQIA ${ }^{+}$não possuem interesse, não só na política, mas em quaisquer outros assuntos de grandes transformações sociais.

\section{O Recrutamento Político, o Financiamento de Campanhas e as Fraudes das Cotas Eleitorais de Gênero}

Embora as eleições do corrente ano tenham registrado acréscimo no número de registro de candidaturas de mulheres e negro ${ }^{10}$, segundo Santos (2016) os fatores conjunturais e estruturais do recrutamento político, enquanto condicionantes da viabilidade de candidaturas, evidenciam que a arena eleitoral ainda se caracteriza como um "espaço privilegiado de seleção das elites políticas".

Para o autor, diferentemente do que ocorre com os campos acadêmico e artístico, o campo político não é capaz de se autonomizar isoladamente devido à dependência do eleitorado nas eleições. Assim, no campo político entra em ação a atuação do capital político, definido como capital de reputação e notoriedade no reconhecimento pelos eleitores e condicionante de êxito eleitoral.

Segundo Santos (2016), o campo político apresenta variáveis como:

O capital cultural (entendido como conhecimentos técnicos específicos) é essencial, visto que detentores de determinadas profissões dispõem dos conhecimentos valorizados no campo (no caso francês, a formação na Escola Nacional de Administração é muito importante para o acesso às competências próprias de político profissional) e do tempo livre para a dedicação à vida política.

\footnotetext{
II No recorte de gênero foram contabilizadas 185.430 (33,42\%) candidaturas femininas e $369.464(66.58 \%)$ masculinas. Além disso, nota-se o aumento de $51 \%$ dos candidatos que se autodeclararam negros, aumento de $2 \%$ em relação ao pleito ocorrido em 2016.
} 
O capital econômico também é importante, ainda mais em um contexto de democracias de massa no qual as eleições têm se tornado "shows midiáticos" e que o papel do marketing político tem ganhado saliência no sucesso/fracasso eleitoral. É nesse quesito que Bourdieu identifica o papel crescente da mídia (principalmente a televisiva) na configuração do campo político e na distribuição do capital político entre os profissionais da política (SANTOS, 2016, p. 152).

Tal estruturação permite o estreitamento da pretensão de votos entre candidatos de um mesmo partido, entre micro e macro agremiações partidárias e entre candidatos dentro de uma mesma pauta de agenda. No que se refere aos membros LBTQIA ${ }^{+}$o capital cultural não se encontra distribuído de maneira proporcional dentro do próprio segmento, pois, segundo Brasil (2020), um reflexo acerca das vulnerabilidades sociais é o nível de escolaridade dos candidatos a cargos eletivos.

Dentro da própria comunidade tais disparidades evidenciam que as candidaturas gays (59,1\%) e lésbicas $(45,1 \%)$ possuem nível superior completo ou em andamento em detrimento das travestis e transexuais que apresentam menores índices de instrução contabilizando $25 \%$ com nível superior completo ou incompleto.

Ainda, no centro da dinâmica do recrutamento eleitoral ocupa espaço central enquanto definidor da distribuição de recursos de financiamento, a figura do "político profissional", visto que são estes que captam parcela relevante do capital político - entendido como capital de reputação fator quase que institucionalizado de êxito dos parlamentares. Dispensa comentários pelas razões já discutidas que esse perfil é formado em sua grande maioria por homens, brancos, de classe média alta, em idade produtiva e com ocupação que lhes permitem dedicação necessária à seara política.

Como a grande maioria das dificuldades das mulheres em ascender à carreira pública são comuns aos indivíduos assumidamente LGBTQIA $^{+}$, o campo político, enquanto dependente de autonomização própria revela-se marcado por assimetrias sociais. A desvantagem dos candidatos em prol das diversidades sexuais e de gêneros na disputa pela arena política tem origem na fase préeleitoral, sendo esta marcada, prioritariamente, por essas marginalidades socioeconômicas.

Por esse ângulo, para que as forças políticas antagônicas sejam equilibradas, é preciso garantir que as condições de recrutamento eleitoral sejam harmoniosas com os demais candidatos de fora da agenda fomentando o capital político e o marketing eleitoral dos candidatos LGBTQIA+, enquanto condicionantes do êxito ou rejeição das candidaturas de modo geral. 
A Lei das Eleições criou o Fundo Especial de Assistência Financeira aos Partidos Políticos, chamado de Fundo Partidário, que encontra previsão no art. 38 da Lei no 9.096 de 19 de setembro de 1995, Lei dos Partidos Políticos, sendo destinados aqueles que, desde que devidamente registrados no TSE, preencham os requisitos elencados no art. $17,83^{\circ}$ da Carta Magna.

Até a publicação da minirreforma eleitoral - Lei no ${ }_{13.165}$, de 29 de setembro de 2015 que altera as a Lei das Eleições e o Código Eleitoral, para reduzir os custos das campanhas eleitorais, simplificar a administração dos Partidos Políticos e incentivar a participação feminina -, a destinação das verbas oriundas do Fundo Partidário aos candidatos de ambos os sexos ficava a cargo dos partidos políticos. Contudo, com a vigência da norma retro mencionada ficou estabelecido o teto mínimo de $5 \% \mathrm{e}$ máximo de $15 \%$ do montante do Fundo Partidário ao financiamento de campanhas femininas.

Nesse sentido, no intuito de inibir as disparidades existentes no campo político quando do recrutamento eleitoral, tanto o TSE quanto o Supremo Tribunal Federal firmaram entendimento de que, no mínimo trinta por cento dos recursos oriundos do Fundo Partidário e do Fundo Especial de Financiamento de Campanha sejam destinados nos pleitos majoritários e proporcionais e, em número mínimo maior e elevado na mesma proporção apresentada nos registros de candidatura (Brasil, 2018).

Parte da doutrina teceu crítica à medida do STF uma vez que a decisão aborda explicitamente o sistema majoritário, quando em verdade as cotas eleitorais de gênero se destinam ao sistema proporcional. Além disso, o tratamento conferido prejudica as verbas oriundas de tais fundos visto que os pleitos majoritários geralmente demandam expressivo valor econômico.

[...] bastará que uma mulher figure como candidata a vice numa chapa majoritária encabeçada por um homem, ou a suplente de senador, para que os recursos destinados a essas chapas possam ser computados na quota, sugando, assim, boa parte dos recursos que deveriam ser destinados às candidaturas beneficiárias da política de quota de gênero (SANTOS, 2020, p. 570).

Modificar a destinação dos recursos de financiamento de campanha às cotas eleitorais de gênero configura ilícito eleitoral, não sendo plausível sequer a doação recíproca entre os candidatos. Ainda, a Resolução do TSE nº 23.610 de 2019, que dispõe sobre propaganda eleitoral, utilização e geração do horário gratuito e condutas ilícitas em campanha, ao regular condutas ilícitas, tema latente no Direito Eleitoral, visa dificultar situações práticas eleitorais que intentem desvirtuar a intenção da ação afirmativa enquanto política pública. 
A busca incessante dos partidos políticos em garantir a cota eleitoral de gênero para obter a destinação de verbas em percentuais firmados em lei do Fundo Partidário, fez erigir uma das novas preocupações da Justiça Eleitoral: a "industrialização das candidaturas femininas laranja”. Conforme já mencionado, constituem candidaturas meramente formais, sem que tenha efetiva participação na disputa e recrutamento ao pleito.

A aferição do ilícito eleitoral da fraude à ação afirmativa em discussão possui realidade material controversa. Além disso, embora se origine durante a fase de registro das candidaturas, seus possíveis sinais de ocorrência tornam-se mais evidentes após realização das eleições. (Santos, 2016).

Vale ressaltar, que muitas agremiações partidárias controlam a utilização dos recursos econômicos oriundos do Fundo Partidário, destinando-os aos nomes que acreditam que obterão maior êxito no pleito ou impulsionam candidatos que formem proporção favorável na assembleia ou câmara legislativa conforme o caso, deixando as candidatas à mercê economicamente e, consequentemente, desestimuladas na corrida, acabam desistindo do recrutamento eleitoral.

$\mathrm{Na}$ hipótese de reconhecimento da conduta ilícita analisada, o encadeamento lógico-jurídico é a desconstituição da decisão que deferiu o Demonstrativo de Regularidade dos Atos Partidários (DRAP) com, ou a superveniente regularização, ou a possibilidade de extinção dos Requerimentos de Registros de Candidaturas (RRC) e demais a eles conexos, podendo, todos os candidatos e seus respectivos suplentes, se eleitos, perderem seus mandatos, não importando o gênero a que pertença. Tal repercussão deve-se à pseudo-competição da disputa por votos que a fraude das cotas desencadeou (Gomes, 2020, p. 568).

Se valendo da Teoria do Impacto Desproporcional ${ }^{\text {II }}$ e utilizando-se de forma análoga ao reconhecimento dado pelo TSE quando da decisão que possibilitou que candidaturas negras recebam financiamento proporcional, ainda que a norma seja exigível apenas nos pleitos de 2022, atribui-se competência ao Congresso Nacional em estabelecer políticas de ações afirmativas ${ }^{12}$ para ampliar a participação política da comunidade LGBTQIA ${ }^{+13}$, atendendo as demandas constitucionais de

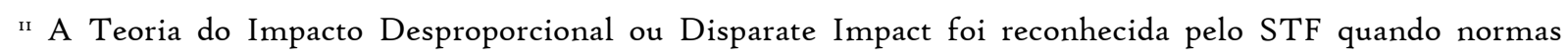
hipoteticamente neutras e, desde a sua origem harmoniosas com a igualdade formal, produzem efeitos que na vida prática são prejudiciais a determinados grupos sociais que já se encontram em estado de marginalização.

${ }^{12}$ Insta salientar, que a própria lei que institui a cota determina a realização de estudos periódicos para aferir os alcances e concretização dos objetivos iniciais.

${ }^{13}$ A Frente Parlamentar pela Cidadania GLBT apresentou o PL no 134 de 2018, Projeto de Lei que Institui o Estatuto da Diversidade Sexual e de Gênero. Apesar da Frente ter sido a responsável pela instituição do Programa Brasil sem Homofobia, em 2004, o Estatuto, que ainda se encontra em pauta para votação, dispõe de 
igualdade não devendo o Poder Judiciário ser protagonista de sua formulação (Brasil, 2020). Assim, tratando de competência privativa da União legislar sobre matéria eleitoral, segundo previsão constitucional, deve a medida ser criada por lei ante a ausência de norma eleitoral no presente sentido, visto que romper com sistemas que endureçam as relações sociais é dever do Estado.

\section{${ }_{4}$ CONCLUSÃO}

Os regimes democráticos ocidentais têm ganhado força para efetivar a vontade da maioria, sendo que a atual configuração das Casas Legislativas brasileiras ainda denota a histórica exclusão social e os filtros institucionais seletivos que anulam a ambição política das minorias e, consequentemente, sua exclusão dos espaços públicos de decisão além do pleno gozo de sua cidadania.

Se a democracia remonta um contexto elitista na sua origem, séculos depois, ainda são as elites contemporâneas ocupantes dos espaços representativos. Por tal razão, não causa aversão o descrédito do papel da política enquanto instrumento de transformação social.

Mesmo com a existência de mecanismos legais criados de modo a reduzir a disparidade de representação participativa, as mulheres ainda sofrem o estigma histórico da sub-representatividade

decorrente da desigualdade de gênero nos âmbitos públicos e particular. À medida que outros espaços sociais acompanham a politização das manifestações de identidades sexuais e de gênero, a política não assim o fazendo - alimentada por ausência no enrijecimento de politicas públicas e um governo imparcial no tratamento conferido aos movimentos contramajoritários que efetivem direitos e garantias destes -, legitima um sistema político-representativo anômalo.

Conforme visto, se as mulheres sofrem o aniquilamento da ambição política e estigma da ausência efetiva de representatividade devido ao fato de, na condição do gênero oposto, serem os homens responsáveis pelos modelos de política e cidadania instaurados e exercidos, a comunidade LGBTQIA $^{+}$, com nula representação, provoca repulsa à hegemonia cis-hetero dominante, líderes de grande parte das agremiações partidárias, por se distanciar das expectativas e construções culturais do gênero que, aprioristicamente, lhe é semelhante. Talvez seja esse o motivo pelo qual a problemática eleitoral dos LGBTQIA $^{+}$nunca ascendeu como uma preocupação de Estado.

dispositivos capazes de regular a representatividade participativa e aperfeiçoar o gozo dos direitos políticos da comunidade LGBTQIA ${ }^{+}$. 
$\mathrm{Na}$ busca por instrumentos jurídico-normativos, são evidenciadas as ações afirmativas, mais especificamente as cotas eleitorais sobre generidade, de modo a legitimar a representatividade participativa das identidades sexuais e de gênero para que se possa expandir, formal e materialmente, as noções atinentes à democracia no sistema legislativo brasileiro.

Para tanto, pelas razões já mencionadas e semelhante ao tratamento conferido pela Justiça Eleitoral aos candidatos negros no corrente ano, válida para os pleitos de 2022, a utilização de recursos oriundos dos fundos de financiamento de campanhas eleitorais previstos na legislação eleitoral deve ser encarada como o principal fator de recrutamento do campo político ante as desvantagens socioeconômicas vivenciadas pelas minorias políticas. Contudo, o sentido de democracia participativa não deve se exaurir nas ações afirmativas eleitorais.

Apesar dos avanços obtidos pela agenda, inúmeros são e serão as dificuldades a serem vivenciadas. Impera a cisão entre a representação descritiva e a substantiva, quando, apesar de o candidato se reconhecer LGBTQIA $^{+}$, não se encontra alinhado às necessidades de atuar em prol da classe a que politicamente pertence. Ainda, há a preocupação com as fraudes das cotas eleitorais que, se existentes entre as candidaturas das mulheres, se perpetuarão outras falsas simulações da realidade, diante da pouca abertura à pauta das diversidades no campo político.

A solução para a sub-representação - principalmente para cargos legislativos no sistema proporcional -, deve perpassar pela instituição de ações afirmativas. Mesmo que seja plausível a adoção de medidas que ampliem a representação política da população LGBTQIA ${ }^{+}$, consiste em obrigação estatal tanto a implementação de cotas eleitorais de gênero às candidaturas quanto o financiamento discriminado pelos partidos políticos a partir do recorte das identidades de gênero e orientação sexual, a ante a carência de fonte legislativa específica.

No Parlamento, é necessário que todos os grupos sociais sejam devidamente representados para regular o funcionamento da democracia e da legitimidade quando da tomada de decisões. A representação substantiva dos LGBTQIA ${ }^{+}$traz consequências positivas, pois retira a falsa impressão de que o segmento não oferece contribuições para a política ou para outras abordagens de transformações sociais.

Ainda, devido ao calendário eleitoral - que prevê a realização das eleições municipais no presente ano -, marcado pelas ingerências pandêmicas, foi possível a aferição do número recorde de candidatos LGBTQIA ${ }^{+}$. Em virtude das datas previstas, não foi suficientemente capaz de analisar 
dados da realidade eleitoral no âmbito estadual e federal de maneira concreta como foi possível nas municipalidades, o que possibilita que a presente pesquisa se opere em seu viés nesses âmbitos.

Nenhum ato de governo é em vão, e de igual maneira é a vontade do legislador. Fica explícito que a ausência de enrijecimento de políticas públicas que estimulem a efetivação de direitos e garantias de um determinado segmento social pode ser entendida como o resultado de um deficiente amparo legislativo conferido pelo sistema político de representação nacional aos movimentos contrahegemônicos, ocasionando ineficácia dos preceitos concretos de democracia. Por essa razão, é de suma importância questionar o atual contexto político-social no qual as variadas formas de subjetividades se encontram enfraquecidas diante da pseudoneutralidade governamental.

\section{REFERÊNCIAS}

Aliança Nacional LGBTI+. Programa Voto com Orgulho. Levantamento de Précandidaturas Assumidamente LGBTI+ nas Eleições 2020. Curitiba, 2020. Disponível em: https://aliancalgbti.org.br/votocomorgulho/. Acesso em: o9 de out. 2020.

Aliança Nacional LGBTI+. Programa Voto com Orgulho. Boletim no 03/2020. Central de Apuração do Programa Voto com Orgulho. Eleição de pessoas LGBTQI+ e aliadas à causa alcança marca histórica. Curitiba, 2020. Disponível em: http://aliancalgbti.org.br/wpcontent/uploads/2020/II/Boletim-No-03.pdf. Acesso em: 17 nov. 2020.

BRASIL. Lei no 9.504, de 30 de setembro de 1997. Estabelece normas para as eleições. Diário Oficial da União, Brasília, DF, or out. 1997. Disponível em: http://www.planalto.gov.br/ccivil_03/leis/l9504.htm. Acesso: 28 set. 2020.

BRASIL. Lei no 12.034 , de 29 de setembro de 2009. Altera as Leis nos 9.096, de 19 de setembro de 1995 - Lei dos Partidos Políticos, 9.504, de 30 de setembro de 1997, que estabelece normas para as eleições, e 4.737, de 15 de julho de 1965 - Código Eleitoral. Diário Oficial da União, Brasília, DF, 30 set. 2009. Disponível em: http://www.planalto.gov.br/ccivil_03/_ato20072010/2009/lei/Li2034.htm. Acesso em: 28 set. 2020.

BRASIL. Lei no 13.165 , de 29 de setembro de 2015. Altera as Leis $\mathrm{n}$ - 9.504, de 30 de setembro de 1997, 9.096, de 19 de setembro de 1995, e 4.737, de I5 de julho de 1965 - Código Eleitoral, para reduzir os custos das campanhas eleitorais, simplificar a administração dos Partidos Políticos e incentivar a participação feminina. Diário Oficial da União, Brasília, DF, 29 set. 2015a. Disponível em: http://www.planalto.gov.br/ccivil_03/_ato20152018/2015/lei/li3165.htm. Acesso em: 28 set. 2020. 
BRASIL. Lei no 13.488, de 6 de outubro de 2017. Altera as Leis $\mathrm{n}$-9.504, de 30 de setembro de I997 (Lei das Eleições), 9.096, de I9 de setembro de 1995, e 4.737, de 15 de julho de 1965 (Código Eleitoral), e revoga dispositivos da Lei $\mathrm{n}^{\mathrm{0}}$ 13.165, de 29 de setembro de 2015 (Minirreforma Eleitoral de 2015), com o fim de promover reforma no ordenamento político-eleitoral. Diário Oficial da União, Brasília, DF, o6 out. 2017a. Disponível em: http://www.planalto.gov.br/ccivil_03/_ato2015-2018/2017/lei/Li3488.htm. Acesso em: 29 set. 2020.

BRASIL. Ministério Público Eleitoral. Consulta. Art. Io, § 3ํㅡㄹ da Lei no 9.504/97 (Lei das Eleições). Cotas. Sexo biológico ou gênero. Mulheres transgêneras e homens transgêneros. Art. I2 da Lei no 9.504/97 (Lei das Eleições). “Nome completo”. Inteligência. Nome registral civil. Nome social. Candidaturas proporcionais e majoritárias. Parecer Consultivo $\mathbf{n}^{\circ}$ 060405458.2017, de 29 jan. 2018. Relator: Ministro Tarcisio Vieira de Carvalho. Disponível em: http://www.mpf.mp.br/pgr/documentos/parecer-pge-trans. Acesso em: 28 set. 2020.

BRASIL. Senado Federal. Projeto de Lei no 2235, de 2019. Altera a Lei no 4.737, de is de julho de 1965 (Código Eleitoral), para estabelecer a reserva de ao menos trinta por cento das cadeiras de Deputado Federal, Deputado Estadual, Deputado Distrital e Vereador para cada um dos sexos e reservar, quando da renovação de dois terços do Senado Federal, uma vaga para candidaturas masculinas e outra vaga para candidaturas femininas. Brasília, 2019. Disponível em:

https://www25.senado.leg.br/web/atividade/materias/-/materia/136302. Acesso: i7 mai. 2020 .

BRASIL. Supremo Tribunal Federal. EMBARGOS DE DECLARAÇÃO EM AÇÃO DIRETA DE INCONSTITUCIONALIDADE. CONSTITUCIONAL E ELEITORAL. EXTEMPORANEIDADE. IMPUGNAÇÃO DA DECISÃO DEDUZIDA ANTERIORMENTE À PUBLICAÇÃO DO ACÓRDÃO. NÃO CONHECIMENTO DOS EMBARGOS. PRECEDENTES. I. Preliminar. Não conhecimento dos embargos por falta de publicação do acórdão. São extemporâneos os embargos de declaração opostos previamente à publicação do acórdão que julga o mérito da ação direta, uma vez que a publicação constitui o próprio objeto dos embargos. Precedentes. 2. Mérito. Embargos de declaração não conhecidos. Acordão em Embargos de Declaração na ADI 5.617. Embargante: Câmara dos Deputados. Relator: Ministro Edson Fachin. AC, 03 out. 2018. Disponível em: http://www.stf.jus.br/arquivo/cms/bibliotecaConsultaProdutoBibliotecaPastaFachin/an exo/ADI56i7ED.pdf. Acesso em: 29 set. 2020.

BRASIL. Tribunal Superior Eleitoral. Dispõe sobre propaganda eleitoral, utilização e geração do horário gratuito e condutas ilícitas em campanha eleitoral. Resolução no 23.610 , de 18 de dezembro de 2019. Diário de Justiça Eletrônico, Brasília, DF, 27 dez. 2019. Disponível em: https://www.tse.jus.br/legislacao/compilada/res/2019/resolucao-no-23-6ro-de-r8-dedezembro-de-2019. Acesso em: 30 set. 2020. 
BRASIL. Tribunal Superior Eleitoral. Estatísticas Eleitorais. Disponível em: http://intero4.tse.jus.br/ords/dwtse/f?p=EST_ELEICAO:HOME. Acesso em: 15 out. 2020.

BRASIL. Tribunal Superior Eleitoral. ELEIÇÕES PROPORCIONAIS - COTA DE GÊNERO - ATENDIMENTO - OPORTUNIDADE. Possível é o atendimento da exigência do parágrafo 3 o do artigo Io da Lei $\mathrm{n}^{\circ}$ 9.504/1997 em data posterior à do limite para requerimento de candidaturas, desde que isso se faça tendo em vista o espaço de tempo assinado no artigo $10, \S 5^{\circ}$, da citada Lei, para a complementação, consideradas as vagas remanescentes, sendo certo que o indeferimento posterior de candidaturas não infirma a observância do sistema de cotas pelo Partido. Acordão em Recurso Especial de no $107079-$ BA. Ministério Público Eleitoral

e Partido do Movimento Democrático Brasileiro (PMDB) - Municipal. Relator: Ministro Marco Aurélio. AC, II dez. 2012. Disponível em: http://temasselecionados.tse.jus.br/temasselecionados/registro-de-candidato/reserva-de-vaga-por-sexo. Acesso em: 17 mai. 2020.

BRITO, Maria Letícia Juliano Diniz. A representação das minorias: análise do debate desenvolvido por Francisco Belisário Soares de Souza e José Alencar. Revista Eletrônica de Humanidades do Curso de Ciências Sociais da UNIFAP. Macapá, v. 9, n. 2, p. 09-22, jul./dez. 2016. ISSN 1984-4352. Disponível em:

https://periodicos.unifap.br/index.php/pracs. Acesso: I8 jul. 2020.

FACULDADE NOBRE DE FEIRA DE SANTANA (FAN). Manual para elaboração de trabalhos técnico-científicos. Feira de Santana: FAN/UNEF, 2017.

FEITOSA, Cleyton. O que afasta a população LGBT da representação política? Justificando, 2020. Disponível em: http://www.justificando.com/2017/o5/II/o-que-afastapopulacao-lgbt-da-representacao-politica/. Acesso: 18 jul. 2020.

FOUCAULT. Michel. Microfísica do Poder. 19. ed. Rio de Janeiro: Graal, 1979.

GOMES, José Jairo. Direito Eleitoral. ı6. ed. São Paulo: Atlas, 2020.

LAKATOS, Eva Maria; MARCONI, Marina de Andrade. Metodologia do Trabalho Científico. 4. ed. São Paulo: Atlas, 1992.

PASSAMANI, Guilherme Rodrigues. Homossexualidades e Ditaduras Militares: os casos de Brasil e Argentina. Fazendo Gênero 9. Diásporas, Diversidades, Deslocamentos. Disponível em: http://www.fg20I0.wwc20I7.eventos.dype.com.br/simposio/view?ID_SIMPOSIO=I8o. Acesso em: 18 mai. 2020. 
PRODANOV, Cleber Cristiano; FREITAS, Ernani Cesar de. Metodologia do Trabalho Científico: Métodos e Técnicas da Pesquisa e do Trabalho Acadêmico. 2: ed. Novo Hamburgo (RS): Universidade Freevale, 2013.

RAMOS, Emerson Erivan de Araújo. Feminismo como Teoria Crítica do Projeto Liberal: A Equidade de Gênero entre o Universal e o Diferenciado. 2014. Dissertação (PósGraduação em Ciências Jurídicas) - Universidade Federal da Paraíba, João Pessoa, 2014. Disponível em: https://repositorio.ufpb.br/jspui/handle/tede/443r?locale=pt_BR. Acesso: I8 mai. 2020.

SPAREMBERGER, Raquel Fabiana Lopes; OLEA, Thais Campos. Cotas Eleitorais de Gênero e Espaços de Decisão: em busca de uma eficiente política pública de inclusão para a promoção de uma democracia real. Revista Direitos Sociais e Políticas Públicas (UNIFAFIBE). Bebedouro, n. I, v. 8, p. 403-428, 2020. ISSN 2318-5732. Disponível em: https://periodicos.unifap.br/index.php/pracs. Acesso: 18 jul. 2020.

TEODORO, Rafael. Cota de Gênero em Eleições Proporcionais: como funcionam?. Politize!, 2020. Disponível em: https://www.politize.com.br/cotas-de-genero-em-eleicoes/. Acesso: 30 set. 2020.

VITAL, Danilo; VALENTE, Fernanda. Fraude por cota de gênero entra na mira do TSE para eleições municipais. Consultor Jurídico, 2020. Disponível em: https://www.conjur.com.br/2020-ago-I5/fraude-cota-genero-vira-desafio-tse-2020. Acesso em: 30 set. 2020 . 